\title{
Benzo[a]pyrene promotes gastric cancer cell proliferation and metastasis likely through the Aryl hydrocarbon receptor and ERK-dependent induction of MMP9 and c-myc
}

\author{
YUCAI WEI ${ }^{1,2^{*}}$, LEI ZHAO ${ }^{1,2^{*}}$, WENTING HE ${ }^{1,2}$, JINGWEI YANG $^{1,2}$, CHUNYU GENG $^{1,2}$,

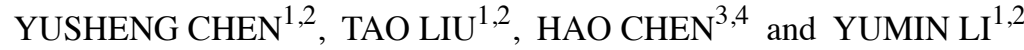 \\ ${ }^{1}$ The Second Hospital of Lanzhou University; ${ }^{2}$ Key Laboratory of Digestive System Tumors of Gansu Province, \\ The Second Hospital of Lanzhou University, Lanzhou, Gansu 730030, P.R. China; ${ }^{3}$ Department of Biochemistry \\ and Molecular Biology and ${ }^{4}$ Divisions of Cardiovascular Medicine and Rheumatology, Department of Medicine, \\ University of Florida College of Medicine, Gainesville, FL 32610, USA
}

Received May 16, 2016; Accepted August 1, 2016

DOI: 10.3892/ijo.2016.3674

\begin{abstract}
Gastric cancer (GC) is the fifth most common cancer worldwide and the third leading cause of global cancer-related death. Benzo[a]pyrene (BaP), a Group I carcinogen categorized by the IARC, is a cumulative foodborne carcinogen and ubiquitous environmental pollutant with potent carcinogenic properties. However, the function and mechanism of $\mathrm{BaP}$ exposure on GC progression remains unclear. We investigated the role of $\mathrm{BaP}$ in human $\mathrm{GC}$ progression to identify potential mechanism underlining its carcinogenic activity. After exposure to various concentrations of BaP, human GC cells SGC-7901 and MNK-45 showed an increased capability of proliferation, migration and invasion. Further study indicated that $\mathrm{BaP}$ promotes the expression of matrix metalloproteinase- 9 (MMP9) and c-myc at mRNA and protein level, and activates Aryl hydrocarbon receptor (AhR) and ERK pathway. Moreover, BaP-induced overexpression of MMP9 and c-myc were attenuated by the ERK inhibitor U0126 and AhR inhibitor resveratrol, respectively. These data suggest that $\mathrm{BaP}$ promotes proliferation and metastasis of GC cells through upregulation of MMP9 and c-myc expression, and this was likely mediated via the AhR and ERK signaling pathway.
\end{abstract}

Correspondence to: Professor Yumin Li, Key Laboratory of Digestive System Tumors of Gansu Province, The Second Hospital of Lanzhou University, 82 Cuiyingmen, Lanzhou, Gansu 730030, P.R. China

E-mail: liym@lzu.edu.cn

*Contributed equally

Key words: benzo[a]pyrene, gastric cancer, proliferation, metastasis, Aryl hydrocarbon receptor, ERK, MMP9, c-myc

\section{Introduction}

Gastric cancer (GC) is the most common cancer worldwide and particularly prevalent in East Asia. Despite a steadily declining incidence, GC is still the third leading cause of global cancerrelated death $(1,2)$. Environmental agents, including a variety of known chemical carcinogens, play an important role in the initiation and progression of GC (3). As a representative member of the polycyclic aromatic hydrocarbon (PAH) family (4), BaP is generated as a result of the incomplete combustion of organic materials from various sources including charcoal-grilled and fried food, wood and tobacco smoke, residential heating, engine exhaust (5-7). Experimental evidence confirmed that BaP leads to tumors in multiple organs of experimental animals, and it has been listed as a human Group I carcinogen by the International Agency for Research on Cancer (IARC) $(8,9)$. Human exposure to environmental $\mathrm{BaP}$ is almost unavoidable through ingestion and inhalation $(10,11)$. It was reported that $\mathrm{BaP}$ absorbed into the body undergo metabolic activation by members of the cellular cytochrome P450 family. BaP metabolism generates several reactive, toxic metabolites that might covalently bind to DNA. The DNA adducts might eventually lead to gene mutation and carcinogenesis if left unrepaired (12).

Stomach, as a primary site of exposure to ingested $\mathrm{BaP}$, is a common target for BaP induced carcinogenesis (13). Feeding laboratory animals with $\mathrm{BaP}$ can induce preneoplastic lesions (such as squamous cell papillomas) and cancer in the stomach (14-16). Early molecular events in the mouse stomach after exposure to $\mathrm{BaP}$ were explored by Labib et al, who documented altered expression of 414 genes, many of which are associated with tumorigenesis and tumor development (7).

$\mathrm{BaP}$ is a potent natural ligand of the AhR which is a ligand-activated transcription factor of the basic helix-loophelix/Per-Arnt-Sim family (17). On binding to its ligands, AhR translocates into the nucleus and dimerizes with its partner molecule Aryl hydrocarbon receptor nuclear translocator (ARNT) $(18,19)$. The AhR-ARNT heterodimer binds to a cognate xenobiotic response element (XRE) and induces a battery of gene expression $(20,21)$. Early studies revealed both 
pro-oncogenic and antitumorigenic role for AhR in multiple tumors $(20,22)$. Some authors have shown that knockdown of the AhR resulted in decreased proliferation, invasion and migration of cancer cell lines $(23,24)$; and transgenic mice that harbor a constitutively active AhR developed stomach tumors (25). On the contrary, it has been reported that mice losing AhR function spontaneously developed colonic tumors (26). The relationship between AhR pathway activation and GC progression is still unknown and need further elucidating.

The signaling kinase ERK, which is a key regulator in cancer progression, plays critical roles in the process of tumor proliferation and metastasis in a variety of cancer types (27). Recent studies identified a relationship between BaP exposure and ERK activation in breast and colon cancer $(28,29)$. However, the relation between BaP activity and ERK pathway has yet to be established.

Epidemiologic study found that long-term exposure to BaP significantly increased the mortality in GC patients (30), suggesting that BaP plays a critical role in $\mathrm{GC}$ advancement. However, little is known about BaP in GC development and progression. In this study, we examined the impact of $\mathrm{BaP}$ exposure on human-derived GC cell lines of different differentiation properties, focusing on the biological effects of $\mathrm{BaP}$ on GC cell proliferation and metastasis, as well as the potential carcinogenic mechanism of $\mathrm{BaP}$ in $\mathrm{GC}$.

\section{Materials and methods}

Cell culture and treatment. The human GC cell lines SGC-7901 and MNK-45 were obtained from the Cell Collection of the Chinese Academy of Sciences (Shanghai, China). These two cell lines were cultured in RPMI-1640 medium supplemented with $10 \%$ fetal bovine serum (FBS, Hyclone), $100 \mathrm{U} / \mathrm{ml}$ of penicillin and $100 \mu \mathrm{g} / \mathrm{ml}$ of streptomycin at $37^{\circ} \mathrm{C}$ in a $5 \% \mathrm{CO}_{2}$ incubator. BaP (Sigma-Aldrich, cat no. B1760), resveratrol (RSV; Sigma-Aldrich, cat no. V90038), ERK1/2 inhibitor U0126 (Cell Signaling, cat no. 9903S) were dissolved in dimethyl sulfoxide (DMSO) and diluted with RPMI-1640 to obtain the desired concentration. Final DMSO concentrations in cultures were $\leq 0.1 \%$.

Cell proliferation assay. The cell proliferation was measured using Cell Counting Kit-8 (CCK-8) assay (Dojindo). Cells were exposed to various concentrations of BaP (i.e., 0.05, 0.1, 0.5, 1, $5 \mu \mathrm{M}$ ) and the vehicle (DMSO) for $48 \mathrm{~h}$ in 96 -well plates. After treatment, $10 \mu \mathrm{l}$ of CCK- 8 was added to the medium and the cells were incubated for another $3 \mathrm{~h}$. The optical density was measured at $450 \mathrm{~nm}$ using a microplate reader (Bio-Tek, USA).

Transwell migration assay and invasion assay. Migration assay, SGC-7901 and MNK-45 cells in serum-free medium were plated in the upper compartment of 24-well Transwell hanging cell culture insert with $8-\mu \mathrm{m}$ micro-porous membranes (Millipore) in 24-well plates. The lower compartments of the plates were filled with RPMI-1640 containing 10\% FBS. After incubated for $16 \mathrm{~h}$ with $\mathrm{BaP}$, cells on the upper surface of the membrane were removed. Cells that migrated to the lower surface were fixed with $4 \%$ paraformaldehyde (PFA) and stained with $0.1 \%$ crystal violet. The stained cells were counted under a microscope.
The invasion assay was performed in a same way as the migration assays, except that the Transwell inserts were coated with Matrigel mixture (BD Biosciences) prior to plating of the cells and the cells were incubated for $48 \mathrm{~h}$.

Real-time PCR. Total RNA was extracted from cells with TRIzol reagent (Takara, cat no. 9108). RNA concentration and purity were measured with microplate reader at A260 and A260/280, respectively. The Prime-Script ${ }^{\mathrm{TM}}$ RT-PCR kit (Takara, cat no. RR047A) was used to reverse-transcribe RNA into cDNA. qRT-PCR amplifications were performed with the Applied Biosystems 7500/7500 Fast Real-Time PCR Software (Applied Biosystems) using the SYBR ${ }^{\circledR}$ Premix Ex Taq ${ }^{\mathrm{TM}}$ II (cat no. RR820A). Reactions were carried out in a $20-\mu 1$ reaction volume following the manufacturer's instructions. The thermal cycle conditions were as follows: $95^{\circ} \mathrm{C}$ for $30 \mathrm{sec}$, followed by 40 cycles of $95^{\circ} \mathrm{C}$ for $5 \mathrm{sec}$ and $60^{\circ} \mathrm{C}$ for $34 \mathrm{sec}$. GAPDH was used as an internal control. The primer sequences were: CYP1A1, forward, 5'-CCATGTCGGCCACGGAGTT-3' and reverse, 5'-ACAGTGCCAGGTGCGGGTT-3'; MMP9, forward, 5'-ACG CACGACGTCTTCCAGTA-3', and reverse, 5'-CCACCTGG TTCAACTCACTCC-3' ; C-myc, forward, 5'-TACAACACCCG AGCAAGGAC-3' and reverse, 5'-AGCTAACGTTGAGGG GCATC-3'; GAPDH: forward, 5'-GCACCGTCAAGGCTGA GAAC-3', and reverse, 5'-TGGTGAAGACGCCAGTGGA-3'. The data were gathered on ABI 7500 One-Step Plus system.

Western blot analyses. Western blot analyses were conducted as previously described (31). After every specific treatment, cells were washed with precooled PBS and lysed on ice with $1 \mathrm{mM}$ phenylmethanesulfonyl fluoride and RIPA buffer (Beyotime, cat no. P0033) containing protease inhibitors phosphatase inhibitors for the extraction of cellular protein. The supernatant was collected and stored in aliquots at $-80^{\circ} \mathrm{C}$ until analysis by western blot analysis. The protein concentration was measured by BCA protein assay system, protein samples were loaded into each well and separated by $10 \%$ sodium dodecyl sulfate-polyacrylamide gel electrophoresis and transferred onto polyvinylidenefluoride (PVDF) membranes. The blots were blocked with 5\% skimmed milk in Tris-buffered saline containing $0.1 \%$ Tween-20 (TBST) for $1 \mathrm{~h}$ at room temperature and then incubated at $4^{\circ} \mathrm{C}$ overnight with primary antibodies against CYP1A1 (Abcam ab126828, 1:1,000), pERK (Abcam ab76165, 1:500), ERK (Abcam ab36991, 1:2,000), MMP9 (Abcam ab137867, 1:1,000) and c-myc (Abcam ab32072, 1:10,000). GAPDH (Bioworld Ap0063, 1:5,000) was used as a loading control. After being washed in TBST three times, the membranes were incubated with horseradish peroxidase-conjugated secondary antibody $(1: 10,000)$ for $1 \mathrm{~h}$ at room temperature. The specific protein bands were visualized using SuperSignal West Pico Chemiluminescent Substrate and imaged using a VersaDoc imaging system (Bio-Rad).

Statistical analysis. The data are shown as the means \pm standard deviation (SD). Statistical analysis was performed using the SPSS 19.0 (IBM, Armonk, NY, USA), and $\mathrm{P}<0.05$ was considered to indicate statistically significant differences. The data were analyzed using ANOVA followed by Dunnett or Bonferroni t-test for multiple comparisons. 


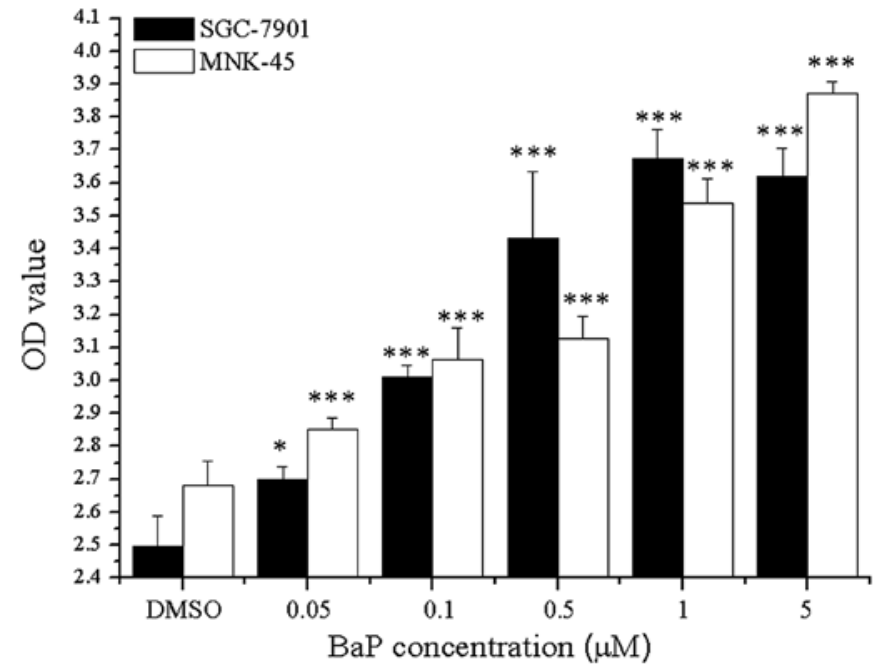

Figure 1. BaP treatment enhances proliferation of GC cells. SGC-7901 and MNK-45 cells exposed to various concentrations of $\mathrm{BaP}$ (as shown above) and vehicle (DMSO) for $48 \mathrm{~h}$. Proliferation of BaP-exposed SGC-7901 and MNK- 45 cells was increased in a dose-dependent manner compared with DMSO treated GC cells.

\section{Results}

BaP enhances proliferation and metastasis of $G C$ cells. Cancer cell proliferation and metastasis are key indices of GC advancement and the major cause of death from the disease (32-34). Therefore, we explored whether BaP promotes the proliferation and metastasis of GC cells. After being treated with BaP, SGC-7901 and MNK-45 cells reached a faster growth rate as demonstrated by the CCK- 8 cell proliferation assay (Fig. 1), The proliferation rate increased with higher dose of BaP, showing a dose-dependent effect of BaP on GC cell growth.

We also assessed the effects of BaP exposure on GC cell migration and invasion, the essential activities that allow tumor cells to spread to multiple organs through blood and lymph circulation. Transwell migration assay showed cell numbers were significantly increased on the lower surface in BaP-exposed SGC-7901 and MNK-45 cells, which indicated cell migration was enhanced by $\mathrm{BaP}$ treatment (Fig. 2). Similarly, BaP-treated SGC-7901 and MNK-45 cells also showed an increased ability of invasion (Fig. 3).
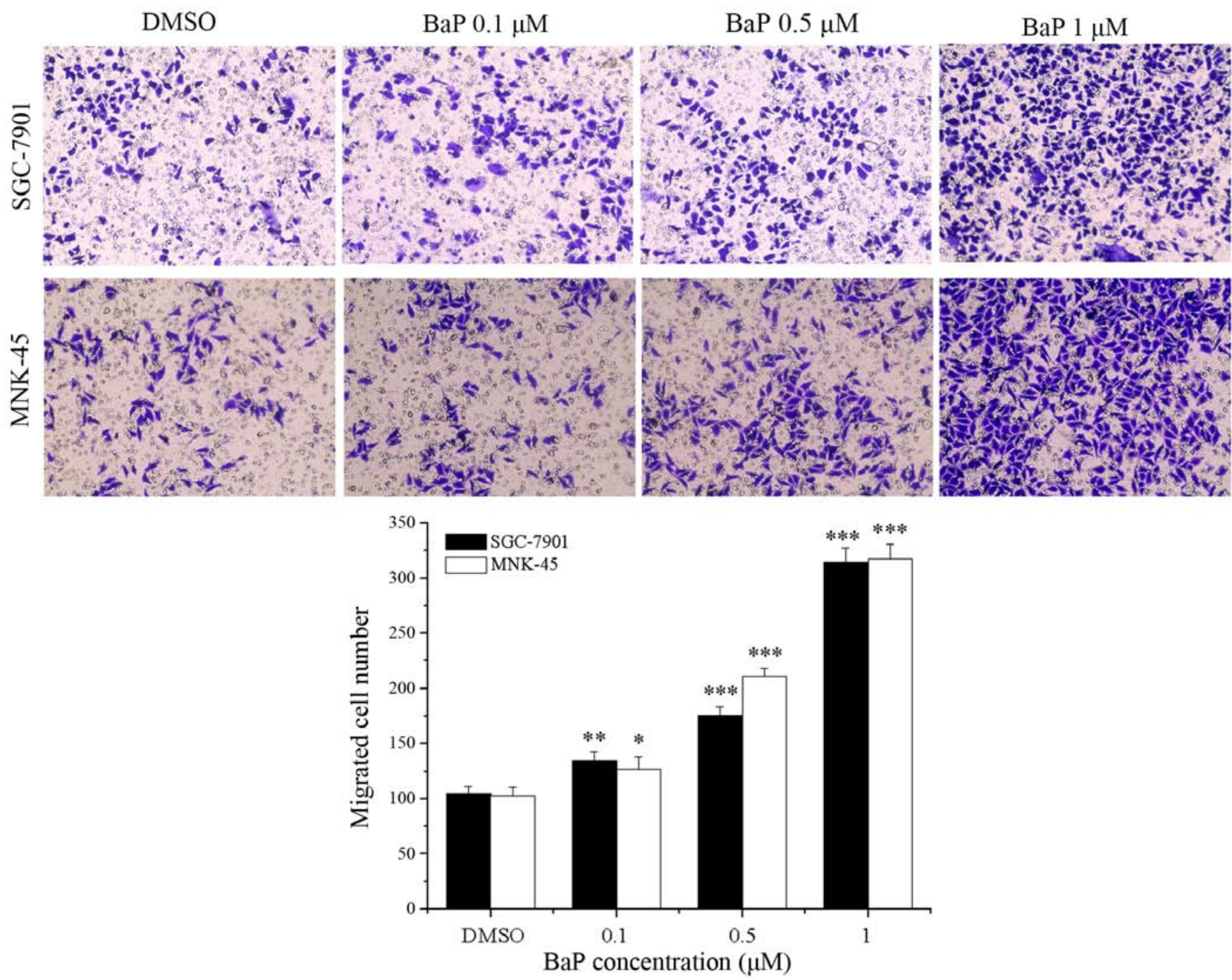

Figure 2. BaP treatment enhances migration of GC cells. SGC-7901 and MNK-45 cells exposed to various concentrations of BaP (as shown above) and vehicle (DMSO). After $16 \mathrm{~h}$, Transwell migration assay showed increased number of GC cells migrated to lower chamber in responding to $\mathrm{BaP}$. ${ }^{*} \mathrm{P}<0.05,{ }^{* *} \mathrm{P}<0.01$,

${ }^{* * *} \mathrm{P}<0.001$, versus control group. 


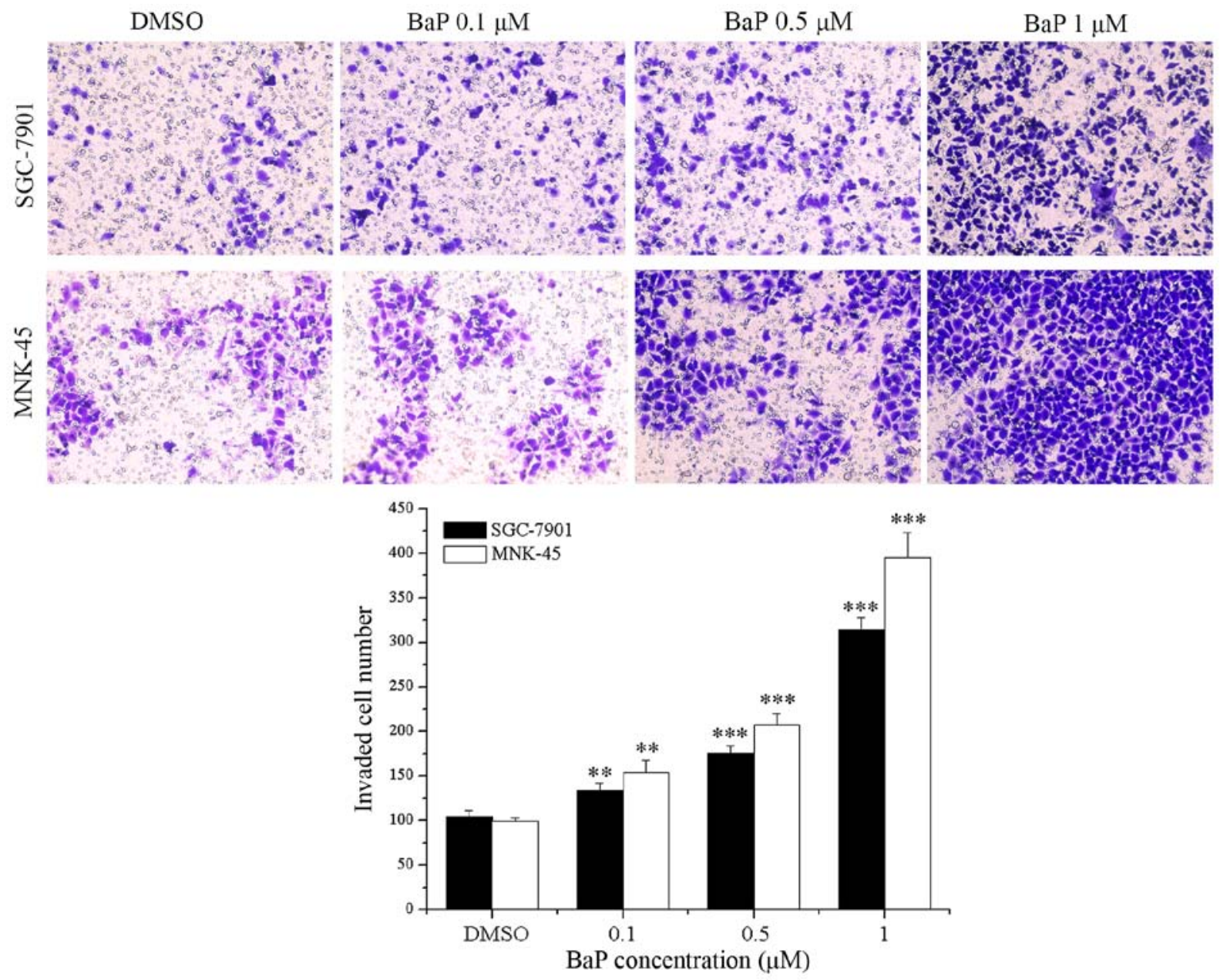

Figure 3. BaP treatment enhances invasion of GC cells. SGC-7901 and MNK-45 cells exposed to various concentrations of BaP (as shown above) and vehicle (DMSO). After $48 \mathrm{~h}$, invasion assay showed increased invasive activity of GC cells. ${ }^{*} \mathrm{P}<0.05,{ }^{* *} \mathrm{P}<0.01,{ }^{* * *} \mathrm{P}<0.001$, versus control group.
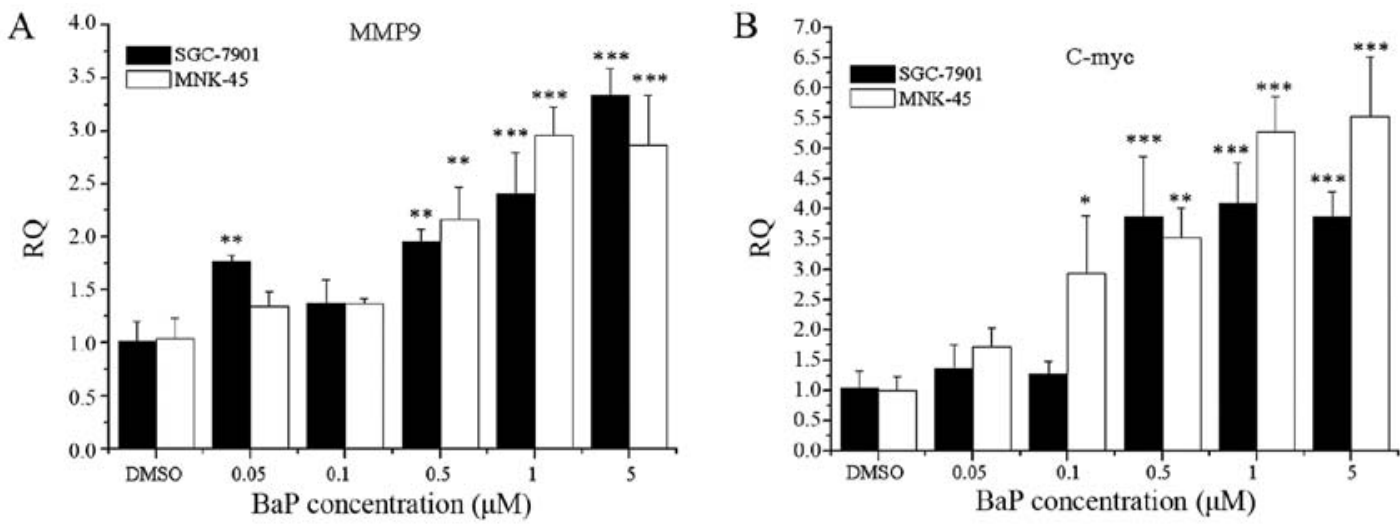

$\mathrm{C}$

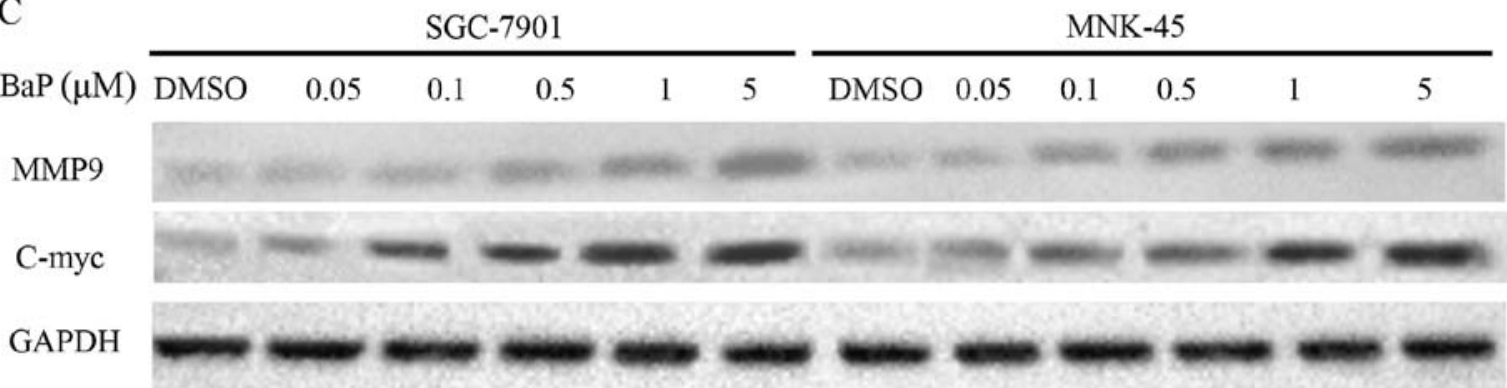

Figure 4. BaP promotes the expression of MMP9 and c-myc. SGC-7901 and MNK-45 cells were exposed to different concentrations (as shown above) of BaP for $48 \mathrm{~h}$, (A and B) RT-PCR analysis of MMP9 and c-myc mRNA expression in a concentration-response. (C) Western blot analysis of MMP9 and c-myc protein expression in a concentration-response. 

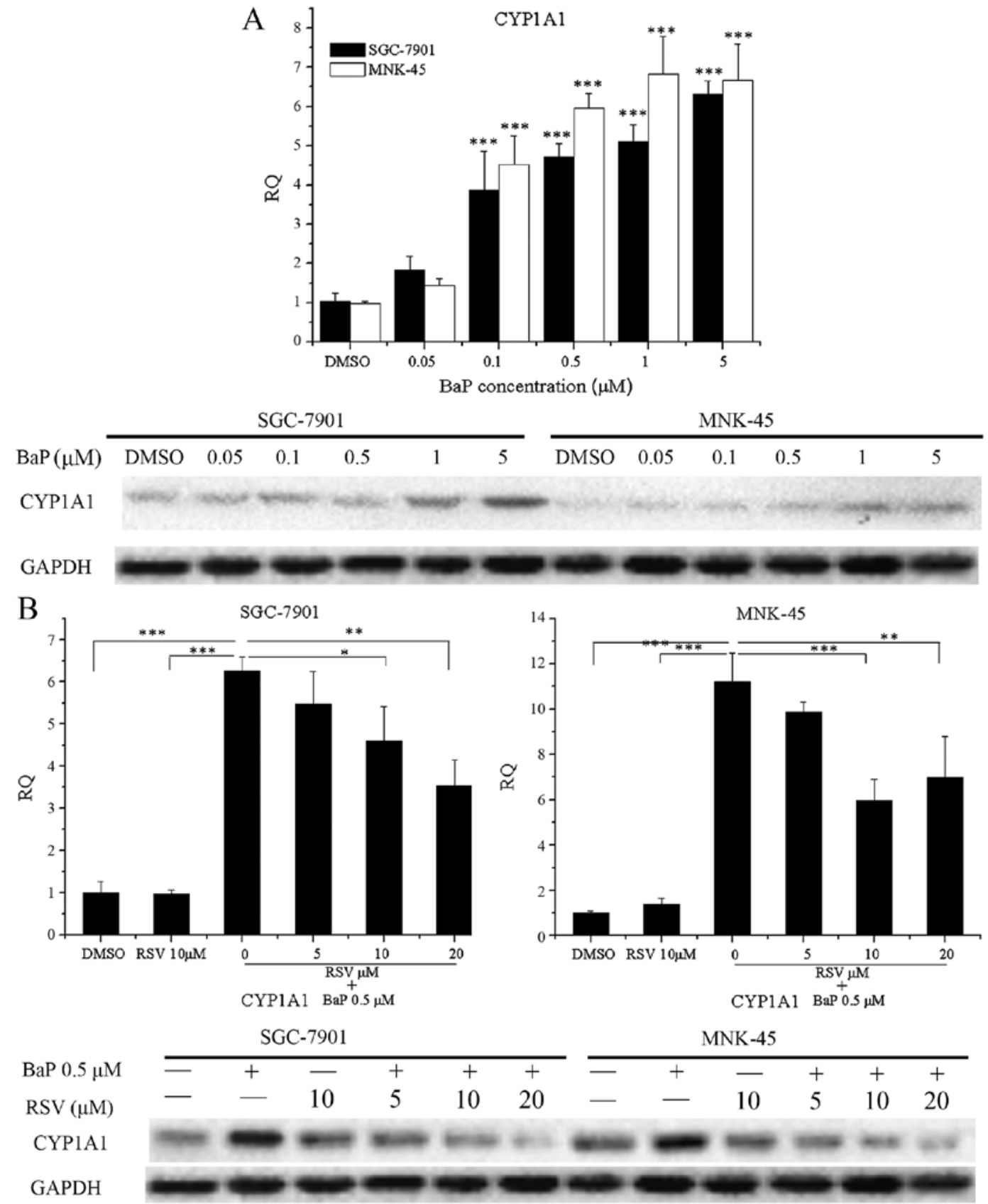

Figure 5. BaP activates the AhR pathway. SGC-7901 and MNK-45 cells were exposed to different concentrations (as shown above) of BaP for $48 \mathrm{~h}$, (A) RT-PCR analysis of CYP1A1 mRNA expression in a concentration-response. Western blot analysis of CYP1A1 protein expression in a concentration-response. After co-treatment with $\mathrm{BaP}(0.5 \mu \mathrm{M})$ and $\mathrm{AhR}$ inhibitor RSV (at different concentrations as shown above) for $48 \mathrm{~h},(\mathrm{~B}) \mathrm{mRNA}$ expression of CYP1A1 was measured by RT-PCR. Protein expression of CYP1A1 was measured by western blot analysis. ${ }^{*} \mathrm{P}<0.05,{ }^{* *} \mathrm{P}<0.01,{ }^{* * *} \mathrm{P}<0.001$.

BaP promotes the expression of MMP9 and c-myc. MMP9 is one of the type IV collagenase/gelatinases that can degrade extracellular matrix (ECM) components and is widely associated with tumor invasion and metastasis (35). A previous study suggested that BaP induced MMP9 expression in breast cancer cells (28). To determine if BaP has the same effect on MMP9 expression in GC cells, we examined the expression of MMP9 in BaP-treated SGC-7901 and MNK-45 cells using RT-PCR and western blotting. Similar to previous reports on breast cancer (28), our results clearly showed that BaP treatment enhanced MMP9 expression in a dose-dependent manner in GC cells (Fig. 4A and C).
C-myc, a classic oncogene, plays an important role in cancer initiation and maintenance (36). When activated in $\mathrm{GC}$ and other cancer cells, c-myc stimulates unlimited proliferation and growth of these cells (37-41). We therefore investigated whether c-myc is induced by BaP treatment in GC cells. As shown in Fig. 4B and 4C, the expression of c-myc was increased following $\mathrm{BaP}$ exposure at the mRNA and protein levels.

BaP activates AhR and ERK pathway. Previous studies have confirmed that $\mathrm{BaP}$ is an exogenous ligand of $\mathrm{AhR}(17)$, and in GC cells the AhR pathway can be activated by another AhR 


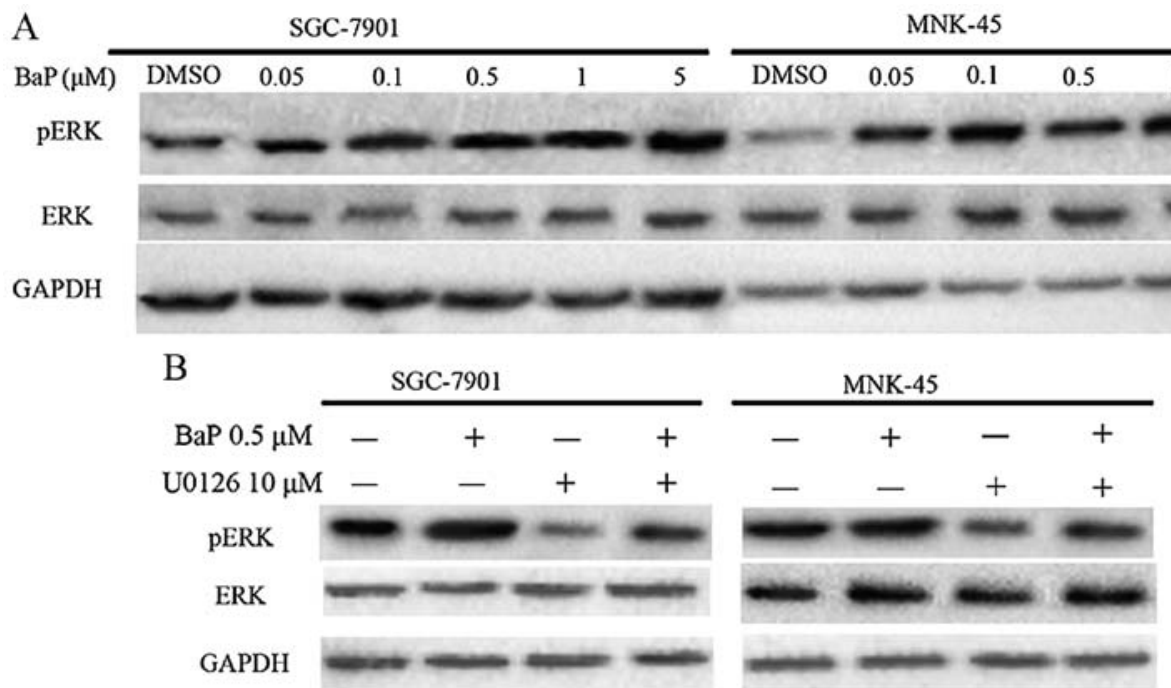

Figure 6. BaP activates the ERK pathway. SGC-7901 and MNK-45 cells were exposed to different concentrations (as shown above) of BaP for $48 \mathrm{~h}$, (A) Western blot analysis of ERK protein expression and phosphorylation in a concentration-response. Cells pretreated with $10 \mu \mathrm{M}$ ERK inhibitor U0126 for $2 \mathrm{~h}$, then co-treated with $\mathrm{BaP}(0.5 \mu \mathrm{M})$ for $24 \mathrm{~h}$, (B) ERK expression and phosphorylation were measured by western blot analysis.
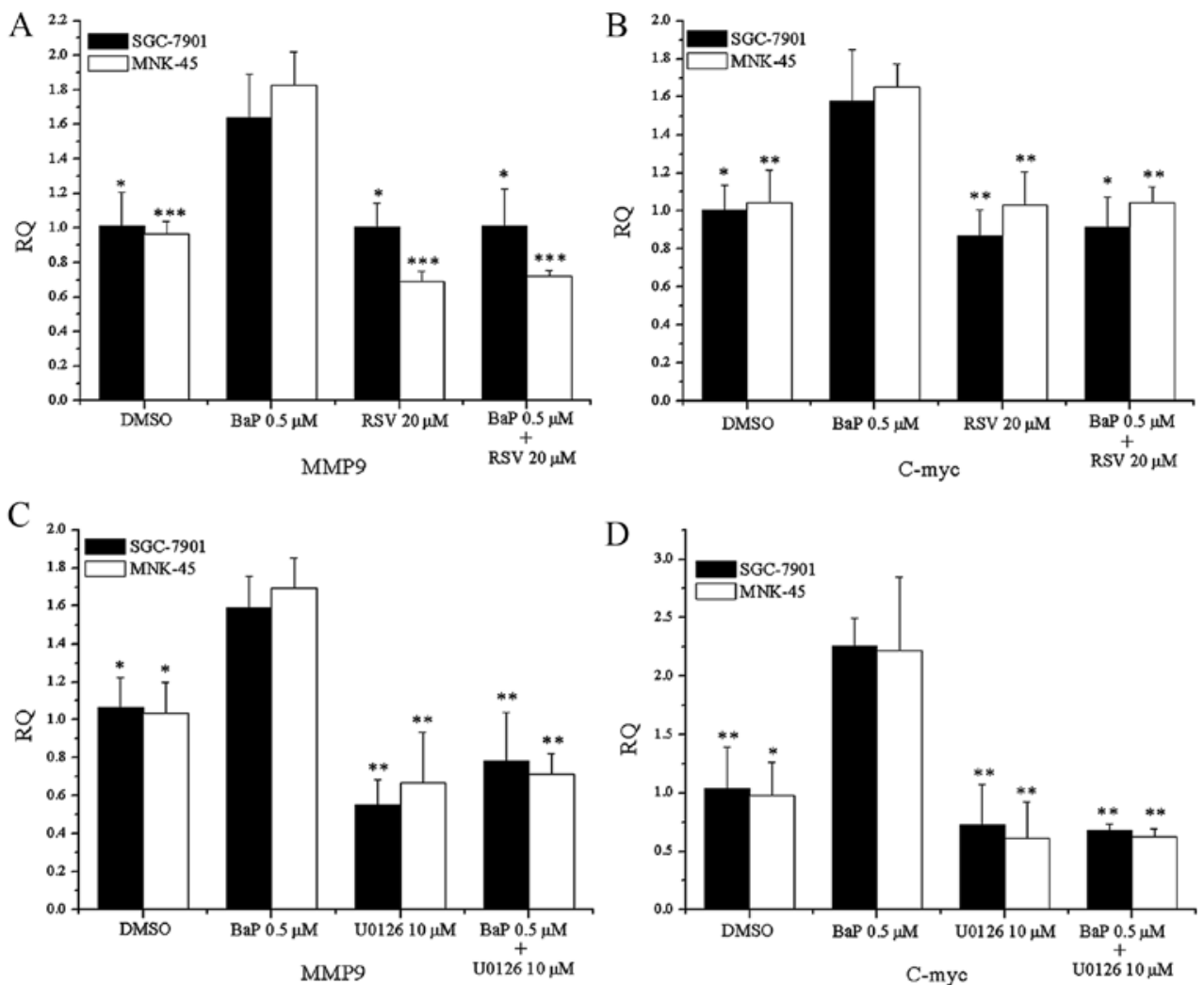

E
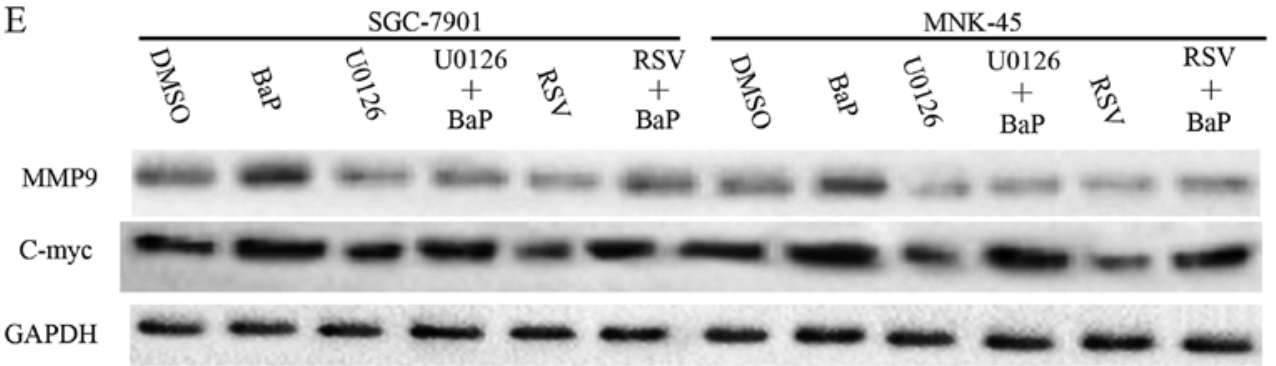

Figure 7. AhR and ERK mediate the expression of MMP9 and c-myc. SGC-7901 and MNK-45 cells were co-treated with BaP $(0.5 \mu \mathrm{M})$ and RSV $(20 \mu \mathrm{M})$ for $48 \mathrm{~h},(\mathrm{~A}, \mathrm{~B}$ and E) the expression level of MMP9 and c-myc were detected by RT-PCR and western blot analysis. Cells pretreated with $10 \mu \mathrm{M}$ U0126 for $2 \mathrm{~h}$, then co-treated with $\mathrm{BaP}(0.5 \mu \mathrm{M})$ for $24 \mathrm{~h},(\mathrm{C}-\mathrm{E})$ the expression level of MMP9 and c-myc were also detected by RT-PCR and western blot analysis. "P<0.05, ${ }^{* *} \mathrm{P}<0.01,{ }^{* * *} \mathrm{P}<0.001$, versus the group of $0.5 \mu \mathrm{M} \mathrm{BaP}$. 


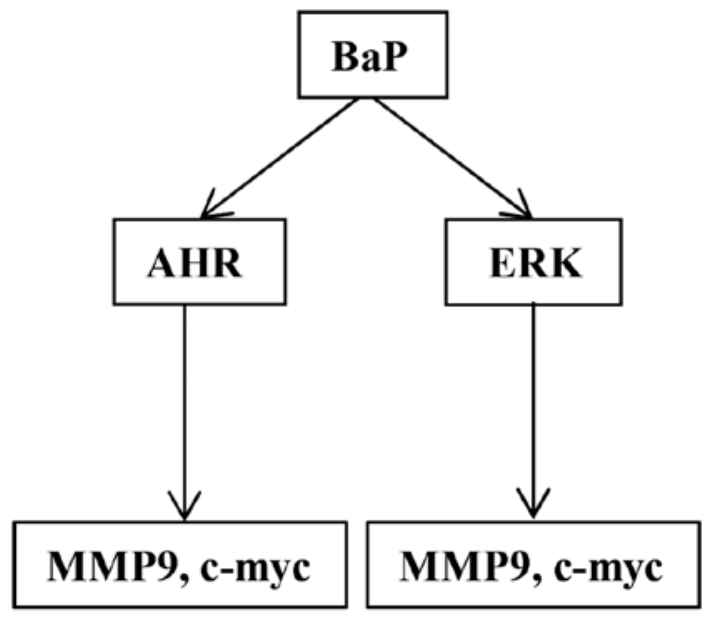

Figure 8. The molecular mechanism of BaP in GC cells. AhR and ERK pathway can be activated after $\mathrm{BaP}$ exposure, and activation of both pathways induces MMP9 and c-myc expression.

ligand 2,3,7,8-tetrachlorodibenzo-p-dioxin (TCDD) (42). To verify whether AhR pathway can also be activated by $\mathrm{BaP}$ in $\mathrm{GC}$ cell lines, the expression of a classic target gene of AhR pathway, cytochrome P450 1A1 (CYP1A1), was detected by RT-PCR and western blotting (43). As shown in Fig. 5A, the expression of CYP1A1 mRNA and protein were elevated in both SGC-7901 and MNK-45 cell lines after BaP treatment. In addition, to clarify whether this BaP-induced CYP1A1 expression is AhR-dependent, AhR pathway was inhibited by an AhR antagonist RSV $(42,44)$. As shown in Fig. 5B, RSV could reverse BaP-induced CYP1A1 expression. These data indicated that BaP can activate AhR pathway in GC cells.

The ERK pathway was also demonstrated to take part in BaP-induced cancer development (28). Western blot analysis showed that pERK protein expression in SGC-7901 and MNK-45 cells were induced by BaP treatment (Fig. 6A). Furthermore, U0126, a known ERK inhibitor, significantly blocked BaP-induced ERK activation (Fig. 6B).

Both AhR and ERK pathways mediate the expression of MMP9 and c-myc. To date, little is known about the impact of BaP on intracellular signal transduction in GC. As shown above, we demonstrated that BaP promoted the expression of MMP9 and c-myc and activated AhR and ERK pathways. Thus, we explored the potential relationship between the two oncogenes and these activated pathways. To elucidate whether the AhR activation really linked to MMP9 and c-myc overexpression, AhR antagonist RSV was used to block the AhR pathway. In the presence of RSV, the overexpression of MMP9 and c-myc induced by BaP were attenuated in SGC-7901 and MNK-45 cells (Fig. 7A, B, E), indicating that AhR pathway mediated the upregulation of MMP9 and c-myc expression by BaP.

In addition, we investigated the role of ERK pathway in the regulation of MMP9 and c-myc expression in BaP-treated GC cells. As shown in Fig. 7C, D and E, inhibition of ERK signaling by U0126 significantly attenuated BaP-induced MMP9 and c-myc expression at the mRNA and protein level. Therefore, the ERK pathway appears to participate in mediation of MMP9 and c-myc expression.

\section{Discussion}

GC is the most common cancer worldwide and the third leading cause of global cancer-related death $(1,2)$. As a Group I carcinogen categorized by the IARC, BaP has been confirmed to induce several types of cancers and play important roles in gastric carcinogenesis $(8,15,16,30)$. In this study, we aimed to explore the effects of $\mathrm{BaP}$ on $\mathrm{GC}$ cell proliferation and metastasis and its regulatory mechanism.

C-myc is overexpressed in GC tissue and can promote GC proliferation and growth in vivo and in vitro $(41,45)$. Our study found that $\mathrm{BaP}$ treatment increased proliferation of $\mathrm{GC}$ cell lines SGC-7901 and MNK-45. Additional evidence showed that exposure to $\mathrm{BaP}$ induced c-myc overexpression, which might promote GC cells proliferation. In regard to metastasis, ECM degradation by matrix metalloproteinases (MMPs) is known to facilitate tumor invasion and metastasis, and MMP9 is the most characterized member of MMPs with strong proteolytic activity in the ECM $(35,46)$. In GC, MMP9 closely associates with the tumor grade and stage and plays important roles in tumor invasion and metastasis $(47,48)$. We found that MMP9 was significantly induced after $\mathrm{BaP}$ exposure and $\mathrm{BaP}$-treated SGC-7901 and MNK-45 cells showed stronger invasive and metastatic ability.

$\mathrm{BaP}$ induces gene mutation and causes deregulation of several proteins mainly through the AhR/CYP450 pathway, thus playing a carcinogenic role in multiple cancers (20). Previous studies have implied that AhR expression is significantly increased in GC tissues and GC cell lines, and its expression was associated with lymph node and distant metastasis in GC patients $(49,50)$. In vitro study showed that AhR pathway activation promoted GC cell invasion (42), while blocking AhR pathway decreases GC cell growth and invasion (51). In vivo experiment also confirm that inhibition of $\mathrm{AhR}$ pathway suppresses GC growth and peritoneal dissemination (49). These results are consistent with our experiment. However, Yin et al reported that activation of AhR pathway by 3,3'-diindolylmethane inhibits GC SGC-7901 cell growth (44). This result is inconsistent with our experiment, the reason may be the difference of the AhR modulator. In addition, AhR can both inhibit and enhance tumor progression, whether AhR plays a pro-oncogenic or an antitumorigenic role likely depends on the cell type and the dominant pathway $(20,22)$. Thus the underlying mechanism between these controversies remains to be further elucidated. Further molecular mechanism research showed AhR modulated c-Jun-dependent induction of MMP9 and Snail expression in GC $(42,49)$. Our study showed that the AhR pathway was activated by $\mathrm{BaP}$ in $\mathrm{GC}$ cell lines and its activation might induce the expression of MMP9 and c-myc. The ERK pathway also has been reported to participate in BaP-induced tumor progression (28). ERK mediates multiple cellular signaling pathways and plays an important role in GC progression $(52,53)$. However, no report on $\mathrm{BaP}$ and ERK in GC exists. This study suggests that BaP activates the ERK pathway and induces the expression of its downstream protein MMP9 and c-myc.

In conclusion, this study demonstrates that $\mathrm{BaP}$ promoted proliferation and metastasis of GC SGC-7901 and MNK-45 cells through upregulation of MMP9 and c-myc expression. Furthermore, AhR and ERK pathways can be activated after 
BaP exposure, and activation of both pathways induces MMP9 and c-myc expression. However, as our study was performed only using GC cell line, further studies using normal gastric mucosa cells are needed, and in vivo studies must be conducted to further verify the findings reported in this study.

\section{Acknowledgements}

This study was supported by the National Natural Science Foundation of China (grant no. 31270532) and Central college basic scientific research foundation of Lanzhou university (grant no. lzujbky-2013-m04).

\section{References}

1. Ferlay J, Soerjomataram I, Dikshit R, Soerjomataram I, Dikshit R, Eser S, Mathers C, Rebelo M, Parkin DM, Forman D and Bray F: Cancer incidence and mortality worldwide: Sources, methods and major patterns in GLOBOCAN 2012. Int J Cancer 136: E359-E386, 2015.

2. Herrero R, Park JY and Forman D: The fight against gastric cancer - the IARC Working Group report. Best Pract Res Clin Gastroenterol 28: 1107-1114, 2014

3. Proctor DM, Gatto NM, Hong SJ and Allamneni KP: Modeof-action framework for evaluating the relevance of rodent forestomach tumors in cancer risk assessment. Toxicol Sci 98: 313-326, 2007.

4. Phillips DH: Fifty years of benzo(a)pyrene. Nature 303: 468-472, 1983.

5. Phillips DH: Polycyclic aromatic hydrocarbons in the diet. Mutat Res 443: 139-147, 1999.

6. Mastrangelo G, Fadda E and Marzia V: Polycyclic aromatic hydrocarbons and cancer in man. Environ Health Perspect 104: 1166-1170, 1996.

7. Labib S, Guo CH, Williams A, Yauk CL, White PA and Halappanavar S: Toxicogenomic outcomes predictive of forestomach carcinogenesis following exposure to benzo(a)pyrene: Relevance to human cancer risk. Toxicol Appl Pharmacol 273: 269-280, 2013

8. Benford D, Dinovi M and Setzer RW: Application of the marginof-exposure (MoE) approach to substances in food that are genotoxic and carcinogenic e.g.: benzo[a]pyrene and polycyclic aromatic hydrocarbons. Food Chem Toxicol 48 (Suppl 1): S42-S48, 2010

9. IARC (International Agency for Research on Cancer): Cadmium and cadmium compounds. IARC Monogr Eval Carcinog Risks Hum 58: 119-237, 1993.

10. Hattemer-Frey HA and Travis CC: Benzo-a-pyrene: Environmental partitioning and human exposure. Toxicol Ind Health 7: 141-157, 1991.

11. Srogi K: Monitoring of environmental exposure to polycyclic aromatic hydrocarbons: A review. Environ Chem Lett 5: 169-195, 2007.

12. Rubin H: Synergistic mechanisms in carcinogenesis by polycyclic aromatic hydrocarbons and by tobacco smoke: A bio-historical perspective with updates. Carcinogenesis 22: 1903-1930, 2001.

13. Lemieux CL, Douglas GR, Gingerich J, Phonethepswath S, Torous DK, Dertinger SD, Phillips DH, Arlt VM and White PA: Simultaneous measurement of benzo[a]pyrene-induced Pig-a and lacZ mutations, micronuclei and DNA adducts in Muta ${ }^{\mathrm{TM}}$ Mouse. Environ Mol Mutagen 52: 756-765, 2011.

14. Culp SJ, Gaylor DW, Sheldon WG, Goldstein LS and Beland FA: A comparison of the tumors induced by coal tar and benzo[a] pyrene in a 2-year bioassay. Carcinogenesis 19: 117-124, 1998.

15. Wester PW, Muller JJ, Slob W, Mohn GR, Dortant PM and Kroese ED: Carcinogenic activity of benzo[a]pyrene in a 2 year oral study in Wistar rats. Food Chem Toxicol 50: 927-935, 2012.

16. Wang Q and Xue Y: Characterization of solid tumors induced by polycyclic aromatic hydrocarbons in mice. Med Sci Monit Basic Res 21: 81-85, 2015.

17. Denison MS, Soshilov AA, He G, DeGroot DE and Zhao B: Exactly the same but different: promiscuity and diversity in the molecular mechanisms of action of the aryl hydrocarbon (dioxin) receptor. Toxicol Sci 124: 1-22, 2011.
18. Hankinson O: Role of coactivators in transcriptional activation by the aryl hydrocarbon receptor. Arch Biochem Biophys 433: 379-386, 2005 .

19. Probst MR, Reisz-Porszasz S, Agbunag RV, Ong MS and Hankinson O: Role of the aryl hydrocarbon receptor nuclear translocator protein in aryl hydrocarbon (dioxin) receptor action. Mol Pharmacol 44: 511-518, 1993.

20. Bersten DC, Sullivan AE, Peet DJ and Whitelaw ML: bHLH-PAS proteins in cancer. Nat Rev Cancer 13: 827-841, 2013.

21. Barouki R, Coumoul X and Fernandez-Salguero PM: The aryl hydrocarbon receptor, more than a xenobiotic-interacting protein. FEBS Lett 581: 3608-3615, 2007.

22. Safe S,Lee SO and Jin UH: Role of the aryl hydrocarbon receptor in carcinogenesis and potential as a drug target. Toxicol Sci 135: $1-16,2013$.

23. Ma Q and Whitlock JP Jr: The aromatic hydrocarbon receptor modulates the Hepa 1c1c7 cell cycle and differentiated state independently of dioxin. Mol Cell Biol 16: 2144-2150, 1996.

24. Portal-Nuñez S, Shankavaram UT, Rao M, Datrice N, Atay S, Aparicio M, Camphausen KA, Fernández-Salguero PM, Chang $\mathrm{H}$, Lin $\mathrm{P}$, et al: Aryl hydrocarbon receptor-induced adrenomedullin mediates cigarette smoke carcinogenicity in humans and mice. Cancer Res 72: 5790-5800, 2012.

25. Andersson P, McGuire J, Rubio C, Gradin K, Whitelaw ML, Pettersson S, Hanberg A and Poellinger L: A constitutively active dioxin/aryl hydrocarbon receptor induces stomach tumors. Proc Natl Acad Sci USA 99: 9990-9995, 2002.

26. Kawajiri K, Kobayashi Y, Ohtake F, Ikuta T, Matsushima Y, Mimura J, Pettersson S, Pollenz RS, Sakaki T, Hirokawa T, et al: Aryl hydrocarbon receptor suppresses intestinal carcinogenesis in ApcMin/+ mice with natural ligands. Proc Natl Acad Sci USA 106: 13481-13486, 2009.

27. Reddy KB, Nabha SM and Atanaskova N: Role of MAP kinase in tumor progression and invasion. Cancer Metastasis Rev 22: 395-403, 2003.

28. Guo J, Xu Y, Ji W, Song L, Dai C and Zhan L: Effects of exposure to benzo[a]pyrene on metastasis of breast cancer are mediated through ROS-ERK-MMP9 axis signaling. Toxicol Lett 234: 201-210, 2015.

29. Xie G, Peng Z and Raufman JP: Src-mediated aryl hydrocarbon and epidermal growth factor receptor cross talk stimulates colon cancer cell proliferation. Am J Physiol Gastrointest Liver Physiol 302: G1006-G1015, 2012.

30. Gibbs GW, Labreche F, Busque MA and Duguay P: Mortality and cancer incidence in aluminum smelter workers: A 5-year update. J Occup Environ Med 56: 739-764, 2014.

31. Zhang L, Li Y, Qiao L, Zhao Y, Wei Y and Li Y: Protective effects of hepatic stellate cells against cisplatin-induced apoptosis in human hepatoma G2 cells. Int J Oncol 47: 632-640, 2015.

32. Winnard PT, Jr., Pathak AP, Dhara S, Cho SY, Raman V and Pomper MG: Molecular imaging of metastatic potential. J Nucl Med 49 (Suppl 2): S96-S112, 2008.

33. Saito H, Osaki T, Murakami D, Sakamoto T, Kanaji S, Oro S, Tatebe $\mathrm{S}$, Tsujitani $\mathrm{S}$ and Ikeguchi M: Macroscopic tumor size as a simple prognostic indicator in patients with gastric cancer. Am J Surg 192: 296-300, 2006.

34. Talamonti MS, Kim SP, Yao KA, Wayne JD, Feinglass J, Bennett CL and Rao S: Surgical outcomes of patients with gastric carcinoma: The importance of primary tumor location and microvessel invasion. Surgery 134: 720-727, discussion 727-729, 2003.

35. Egeblad $M$ and Werb Z: New functions for the matrix metalloproteinases in cancer progression. Nat Rev Cancer 2: 161-174, 2002.

36. Gabay M, Li Y and Felsher DW: MYC activation is a hallmark of cancer initiation and maintenance. Cold Spring Harb Perspect Med 4: 4, 2014

37. Felsher DW: Cancer revoked: Oncogenes as therapeutic targets. Nat Rev Cancer 3: 375-380, 2003.

38. van Riggelen J, Yetil A and Felsher DW: MYC as a regulator of ribosome biogenesis and protein synthesis. Nat Rev Cancer 10: 301-309, 2010.

39. Dang CV: MYC on the path to cancer. Cell 149: 22-35, 2012.

40. Dang CV: c-Myc target genes involved in cell growth, apoptosis, and metabolism. Mol Cell Biol 19: 1-11, 1999.

41. Zhang EB, Han L, Yin DD, Kong R, De W and Chen J: c-Mycinduced, long, noncoding H19 affects cell proliferation and predicts a poor prognosis in patients with gastric cancer. Med Oncol 31: 914, 2014. 
42. Peng TL, Chen J, Mao W, Song X and Chen MH: Aryl hydrocarbon receptor pathway activation enhances gastric cancer cell invasiveness likely through a c-Jun-dependent induction of matrix metalloproteinase-9. BMC Cell Biol 10: 27, 2009.

43. Okey AB: An aryl hydrocarbon receptor odyssey to the shores of toxicology: The Deichmann Lecture, International Congress of Toxicology-XI. Toxicol Sci 98: 5-38, 2007.

44. Yin XF, Chen J, Mao W, Wang YH and Chen MH: A selective aryl hydrocarbon receptor modulator 3,3'-Diindolylmethane inhibits gastric cancer cell growth. J Exp Clin Cancer Res: 46, 2012.

45. Li HJ, Che XM, Zhao W, He SC, Zhang ZL, Chen R, Fan L and Jia ZL: Diet-induced obesity promotes murine gastric cancer growth through a nampt/sirt1/c-myc positive feedback loop. Oncol Rep 30: 2153-2160, 2013.

46. Deryugina EI and Quigley JP: Matrix metalloproteinases and tumor metastasis. Cancer Metastasis Rev 25: 9-34, 2006.

47. Zhang BG, Du T, Zang MD, Chang Q, Fan ZY, Li JF, Yu BQ, $\mathrm{Su}$ LP, Li C, Yan C, et al: Androgen receptor promotes gastric cancer cell migration and invasion via AKT-phosphorylation dependent upregulation of matrix metalloproteinase 9. Oncotarget 5: 10584-10595, 2014.

48. Parsons SL, Watson SA, Collins HM, Griffin NR, Clarke PA and Steele RJ: Gelatinase (MMP-2 and -9) expression in gastrointestinal malignancy. Br J Cancer 78: 1495-1502, 1998.
49. Lai DW, Liu SH, Karlsson AI, Lee WJ, Wang KB, Chen YC, Shen CC, Wu SM, Liu CY, Tien HR, et al: The novel Aryl hydrocarbon receptor inhibitor biseugenol inhibits gastric tumor growth and peritoneal dissemination. Oncotarget 5: 7788-7804, 2014.

50. Peng TL, Chen J, Mao W, Liu X, Tao Y, Chen LZ and Chen MH: Potential therapeutic significance of increased expression of aryl hydrocarbon receptor in human gastric cancer. World J Gastroenterol 15: 1719-1729, 2009.

51. Yin XF, Chen J, Mao W, Wang YHand Chen MH: Downregulation of aryl hydrocarbon receptor expression decreases gastric cancer cell growth and invasion. Oncol Rep 30: 364-370, 2013.

52. Qian J, Kong X, Deng N, Tan P, Chen H, Wang J, Li Z, Hu Y, Zou W, Xu J, et al: OCT1 is a determinant of synbindin-related ERK signalling with independent prognostic significance in gastric cancer. Gut 64: 37-48, 2015.

53. Xu X, Liu Z, Fang M, Yu H, Liang X, Li X, Liu X, Chen C and Jia J: Helicobacter pylori CagA induces ornithine decarboxylase upregulation via Src/MEK/ERK/c-Myc pathway: Implication for progression of gastric diseases. Exp Biol Med (Maywood) 237: 435-441, 2012. 